\title{
Evaluation of Anxiety and Depression in Idiopathic Pulmonary Fibrosis
}

\author{
Derya Yenibertiz ${ }^{1}$, Berna Akıncı Özyürek ${ }^{1}$, Mehmet Sinan Aydın², Yurdanur Erdoğan ${ }^{1}$ \\ ${ }^{1}$ University of Health Sciences, Ataturk Chest Diseases and Chest Surgery Training and Research Hospital, Department of \\ Pulmonology, Ankara, Turkey, \\ ${ }^{2}$ University of Health Sciences, Ataturk Chest Diseases and Chest Surgery Training and Research Hospital, Department of \\ Psychiatry, Ankara, Turkey,
}

Received: 02 October 2020, Accepted: 09 December 2020, Published online: 31 December 2020

(C) Ordu University Institute of Health Sciences, Turkey, 2020

\begin{abstract}
Objective: Depression and anxiety are the comorbid diseases of Idiopathic Pulmonary Fibrosis (IPF) and these diseases are more frequently in patients with serious progressive types of IPF. The aim of this study was to use the Hospital Anxiety and Depression Scale (HADS) to evaluate the levels of depression and anxiety in IPF patients.
\end{abstract}

Methods: A total of 27 patients were included to the study. Demographic characteristics, pulmonary function tests, GAP indexes (gender, age, and physiology), 6-minute walk test (MWT) values were recorded from the patient files. To measure the levels of anxiety and depression in patients with IPF, the validated Turkish version of the HADS, including 14 questions, was used.

Results: Anxiety was determined in $33.3 \%$ of the patients and depression was detected in $37 \%$ of the patients. The patients' avearage anxiety score was 5.5 and the mean depression score was 6.2. Desaturation in patients with anxiety was significantly higher $(\mathrm{p}<0.05)$ and was found to be higher in patients with depression $(\mathrm{p}<0.05)$. DLCO levels were detected to be lower in patients with depression $(\mathrm{p}<0.05)$.

Conclusion: The quality of life of patients diagnosed with IPF can be improved by psychiatric assessment and adequate supportive care, including antidepressant medication and psychological therapy.

Key words: Anxiety, depression, Idiopathic Pulmonary Fibrosis

Suggested Citation: Yenibertiz D, Akinci Özyürek B, Aydin MS, Erdoğan Y. Evaluation of Anxiety and Depression in Idiopathic Pulmonary. Middle Black Sea Journal of Health Science, 2020; 6(3):333-339.

\section{Address for correspondence/reprints:}

Derya Yenibertiz

Telephone number: +90 (505) 2703553

ORCID-ID 0000-0002-1783-4015

E-mail: yenibertizderya@gmail.com

DOI: $10.19127 / \mathrm{mbsjohs.} 818494$

\section{Introduction}

Idiopathic pulmonary fibrosis (IPF) is a chronic, incurable disease with unexplained etiology. It is characterized with a gradual and permanent decrease in lung capacity and is mostly seen in elderly men with a mean life span of 2.5-3.5 years (Raghu et al., 2018). It is characterized by severe fibrosis and lung transplantation is still the most common treatment in appropriate patients. IPF has a severe impact on quality of life and its incidence is increasing. The presence of progressive dyspnea and dry cough that deteriorates the quality of life of IPF patients, the development of hypoxia with the progression of the 
disease, and the lack of definitive treatment of the disease cause an increased tendency to anxiety and depression. In patients with chronic illnesses, depression is 1.5-7 times more common than in the population overall (Zheng et al.,1997; Solano et al., 2006; Moussavi et al., 2007). Mechanisms of the relationship between depression and IPF and the long-term effect of depression on IPF have not been identified. The prevalence of depression is $21-49 \%$ and the prevalence of anxiety in IPF patients is $27-$ $31 \%$. (Ryerson et al., 2011; Ryerson et al., 2012; Akhtar et al., 2013; Holland et al., 2014).

Anxiety and depression are more commonly identified in serious and progressive forms of IPF, (Pink K et al., 2014). Psychological problems, which are the secondary consequences of chronic lung diseases, are often ignored. Dyspne, dry resistant cough, loss of independence, feelings of social isolation and insufficient sleep are among the leading causes of psychological distress (Akhtar et al., 2013). There is a mutual interaction of dyspnea and depression. While dyspne can cause depressive symptoms, on the contrary, depression can exacerbate the perception of respiratory symptoms (Ryerson et al., 2012).

Depression and anxiety should be regularly scanned in patients with IPF, and proper supportive managements, including antidepressants and anxiolytics. Psychological support and pulmonary rehabilitation were suggested to manage anxiety and depression and to improve the quality of life (Yalnız E et al., 2019).

The relationship between anxiety and depression with severity and progression of IPF disease, the effect of these diseases on clinical outcomes of IPF and the effects of treatment of anxiety and depression on pulmonary function tests are not fully clarified in the literature.

We aimed to evaluate the levels of depression and anxiety in IPF and to examine whether the functional severity of the illness was associated with the depression and anxiety score in this study.

\section{Methods}

A single-center, retrospective research was conducted on patients with IPF, followed up and treated in the 8th clinic of our hospital. A total of 27 IPF patients were evaluated in this study. Patients who didn't fully answer the questions and had depression/anxiety before the diagnosis of IPF, had malignancy or an unstable medical condition or had missing data were excluded from the study. Informed consents based on institutional guidelines were taken from all patients. Approval for the study was granted by the medical training board of our hospital. (Approval number and date: 615 / 23.01.2019). Diagnosis of all patients was made clinically, radiologically, or pathologically based on the American Thoracic Society (ATS)/ European Respiratory Society (ERS)/ Japanese Respiratory Society (JRS)/The Latin American Thoracic Association (ALAT) statement (Raghu et al., 2018). Demographic characteristics, pulmonary function tests, DLCO (Diffusing capasity of the lungs for carbon monoxide), GAP (gender, age, and physiology) indexes, 6-minute walk test (MWT) values, treatment information were recorded from the patient files. The staging of IPF patients were evaluated according to the symptoms, findings from high resolution computed tomography (HRCT) and pulmonary function test (PFT). Desaturation was defined as a decrease of $4 \%$ or more in the $\mathrm{O} 2$ saturation in the 6-MWT which was applied at the last visit of the IPF patients. To measure the levels of anxiety and depression in IPF, the validated Turkish version of the HADS (Hospital Anxiety and Depression Scale) including 14 questions was used. The test was carried out at the last hospital visit, so that each patient was at different follow-up periods of the disease. Seven items for depression (HADS-D) and seven items for anxiety (HADS-A) are included in the HADS, in addition there are scores between 0 to 21 points in each subscale. (Aydemir et al., 1997). The scores $\geq 8$ on both HADS-D and HADS-A, respectively, show clinically relevant depression and anxiety. Although there is no diagnostic scale, patients with violence above these scores are candidates for clinical evaluation

\section{Statistical Analyses}

The Statistical Package for the Social Sciences (SPSS) version 22 was used for the statistical analyses. The mean, standard deviation, median, minimum, maximum, frequency and ratio values were utilized in the presentation of the descriptive data of the study. The distribution of variables was measured with the kolmogorov simirnov test. MannWhitney $\mathrm{u}$ test was used to analyze quantitative independent data. Chi-square test was used in the analysis of qualitative independent data, and fischer test was used when chi-square test conditions were not met. A value of $\mathrm{p}<0.05$ was considered statistically significant. 


\section{Anxiety and Depression in Idiopathic Pulmonary Fibrosis}

\section{Results}

Twenty seven patients diagnosed with IPF were investigated in this study. Twenty six patients were male, and 1 patient was female. The average age of the patients was $65.6 \pm 7.6$ years. The General characteristics of the patients are demonstrated in table 1.

Table 1. The general characteristics of the patients

\begin{tabular}{|c|c|c|c|}
\hline & & $\mathrm{n}$ & $\%$ \\
\hline \multicolumn{4}{|l|}{ Gender } \\
\hline & Female & 1 & $3.7 \%$ \\
\hline & Male & 26 & $96.3 \%$ \\
\hline \multicolumn{2}{|c|}{ Comorbitdiy } & 14 & $51.9 \%$ \\
\hline & Lung cancer & 1 & $3.7 \%$ \\
\hline & OSAS & 7 & $25.9 \%$ \\
\hline & GERD & 12 & $44.4 \%$ \\
\hline & Respiratory failure & 10 & $37.0 \%$ \\
\hline \multicolumn{4}{|l|}{ Smoking } \\
\hline & Never & 5 & $18.5 \%$ \\
\hline & Exsmoker & 18 & $66.7 \%$ \\
\hline & Smoker & 4 & $14.8 \%$ \\
\hline \multicolumn{4}{|c|}{ Desaturation } \\
\hline & No & 1 & $3.7 \%$ \\
\hline & Mild & 16 & $59.3 \%$ \\
\hline & Moderate & 3 & $11.1 \%$ \\
\hline & Severe & 7 & $25.9 \%$ \\
\hline \multicolumn{4}{|l|}{ Stage } \\
\hline & Low & 16 & $59.3 \%$ \\
\hline & Mild & 5 & $18.5 \%$ \\
\hline & Severe & 16 & $22.2 \%$ \\
\hline \multicolumn{4}{|l|}{ Medicine } \\
\hline & Nintedanib & 2 & $7.4 \%$ \\
\hline & Pirfenidon & 25 & $92.6 \%$ \\
\hline
\end{tabular}

The average GAP index was 3 and the assessment of the functional condition of IPF patients is demonstrated in table 2 .

Table 2. Evaluation of the functional status of IPF patients

\begin{tabular}{ll}
\hline & mean \pm sd \\
\hline GAP index & $3.9 \pm 1.7$ \\
\hline $6 \mathrm{MWT} / \mathrm{m}$ & $407.2 \pm 108.7$ \\
\hline $\mathrm{DLCO}$ & $57.0 \pm 19.4$ \\
\hline $\mathrm{DLCO} / \mathrm{VA}$ & $85.8 \pm 27.5$ \\
\hline $\mathrm{FVC}$ & $67.8 \pm 15.5$ \\
\hline $\mathrm{FEV}$ & $72.9 \pm 16.5$ \\
\hline $\mathrm{FEV}_{1} / \mathrm{FVC}$ & $84.3 \pm 5.3$ \\
\hline $\mathrm{SPO}_{2}$ & $93.1 \pm 4.5$ \\
\hline
\end{tabular}

GAP: Gender-Age-Physiology, 6- (MWT): 6-minute walk test, FEV1: Forced Expiratory Volume in one second, FVC: Forced vital capacity, SPO2: Saturation of Peripheral Oxygen, DLCO: Diffusing capacity of the lungs for carbon monoxide
All patients were having antifibrotic treatment. The mean anxiety score of the patients was 5.5 and the mean depression score was 6.2. Anxiety was found in $33.3 \%$ of the patients and depression was determined in $37 \%$ of the patients (Table 3).

Table 3. The results of HADS

\begin{tabular}{|c|c|c|}
\hline & $\mathrm{n}$ & $\%$ \\
\hline HADS-A & $5.5 \pm 5.7($ mean $\pm s d)$ & \\
\hline \multicolumn{3}{|l|}{ Anxiety } \\
\hline$(-)$ & 18 & $66.7 \%$ \\
\hline$(+)$ & 9 & $33.3 \%$ \\
\hline HADS-D & $6.2 \pm 5.7$ (mean $\pm s d)$ & \\
\hline \multicolumn{3}{|l|}{ Depression } \\
\hline$(-)$ & 17 & $63.0 \%$ \\
\hline$(+)$ & 10 & $37.0 \%$ \\
\hline Total score & $11.7 \pm 11.0$ (mean \pm sd) & \\
\hline
\end{tabular}

HADS-A: Hospital Anxiety and Depression Scale-Anxiety; HADS-D: Hospital Anxiety and Depression Scale-Depression

The comparison between patients with and without anxiety is shown in table 4 and the comparison between patients with and without depression is shown in table 5, based on the GAP Index values (score and stage), the results of 6-MWT, DLCO and PFT, $\mathrm{SP}_{2}$, desaturation and stage. DLCO levels were found to be lower in the depression group than in the non-depression group $(\mathrm{p}<0.05)$, they didn't vary significantly in the anxiety and nonanxiety group $(p>0.05)$. Desaturation rates in the patients with anxiety/depression were found to be significantly higher than in the non-anxiety/non depression population $(\mathrm{p}<0.05)$. 
Table 4. The comparison between patients with and without anxiety

\begin{tabular}{|c|c|c|c|c|c|c|c|}
\hline & & \multicolumn{3}{|c|}{ Anxiety(-) } & \multicolumn{2}{|l|}{ Anxiety(+) } & \multirow[t]{2}{*}{$\mathrm{p}$} \\
\hline & & & $\pm \mathrm{sd} / \mathrm{n}-\%$ & $\begin{array}{l}\text { Median } \\
(\% 25-\% 75)\end{array}$ & Mean \pm sd $/ \mathrm{n}-\%$ & $\begin{array}{l}\text { Median } \\
(\% 25-\% 75)\end{array}$ & \\
\hline \multicolumn{2}{|l|}{ GAP Index } & & $4.0 \pm 1.645$ & 3.5 & $3.56 \pm 2.007$ & 3 & $0.432^{\mathrm{m}}$ \\
\hline \multirow{3}{*}{ GAP } & Stage I & 9 & $50.0 \%$ & & $55.6 \%$ & & \multirow{3}{*}{$0.785^{\times 2}$} \\
\hline & Stage II & 5 & $27.8 \%$ & & $11.1 \%$ & & \\
\hline & Stage III & 4 & $22.2 \%$ & & $33.3 \%$ & & \\
\hline 6MWT (m) & & & $423.4 \pm 121.6$ & 480.0 & $376.7 \pm 75.5$ & 360.0 & $0.160^{\mathrm{m}}$ \\
\hline DLCO & & & $61.9 \pm 18.5$ & 65.0 & $48.8 \pm 19.18$ & 46.0 & $0.114^{\mathrm{m}}$ \\
\hline DLCO/VA & & & $93.1 \pm 23.66$ & 84.0 & $73.4 \pm 30.42$ & 85.0 & $0.221^{\mathrm{m}}$ \\
\hline FEV1 & & & $74.0 \pm 15.85$ & 74.0 & $70.6 \pm 18.61$ & 73.0 & $0.681^{\mathrm{m}}$ \\
\hline FVC & & & $69.1 \pm 14.8$ & 72.5 & $66.2 \pm 17.36$ & 67.0 & $0.571^{\mathrm{m}}$ \\
\hline $\mathrm{FEV}_{1} / \mathrm{FVC}$ & & & $83.9 \pm 5,624$ & 83.5 & $85.2 \pm 4.684$ & 86.0 & $0.518^{\mathrm{m}}$ \\
\hline $\mathrm{SPO}_{2}$ & & & $93.8 \pm 2.915$ & 95.0 & $91.7 \pm 6.745$ & 94.0 & $0.658^{\mathrm{m}}$ \\
\hline \multirow{4}{*}{ Desaturation } & None & 1 & $5.6 \%$ & & $0.0 \%$ & & \multirow{4}{*}{$0.024^{\times 2}$} \\
\hline & Mild & 13 & $72.2 \%$ & & $33.3 \%$ & & \\
\hline & Moderate & 1 & $5.6 \%$ & & $22.2 \%$ & & \\
\hline & Severe & 3 & $16.7 \%$ & & $44.4 \%$ & & \\
\hline \multirow{3}{*}{ Stage } & Mild & 13 & $72.2 \%$ & & $3.33 \%$ & & \multirow{3}{*}{$0.053^{x^{2}}$} \\
\hline & Moderate & 3 & $16.7 \%$ & & $2.22 \%$ & & \\
\hline & Severe & 2 & $11.1 \%$ & & $4.44 \%$ & & \\
\hline \multicolumn{6}{|c|}{${ }^{\mathrm{m}}$ Mann -Whitney U Test $/{ }^{\times 2}$ Chi Square Test } & & \\
\hline
\end{tabular}

Table 5. The Comparison between patients with and without depression

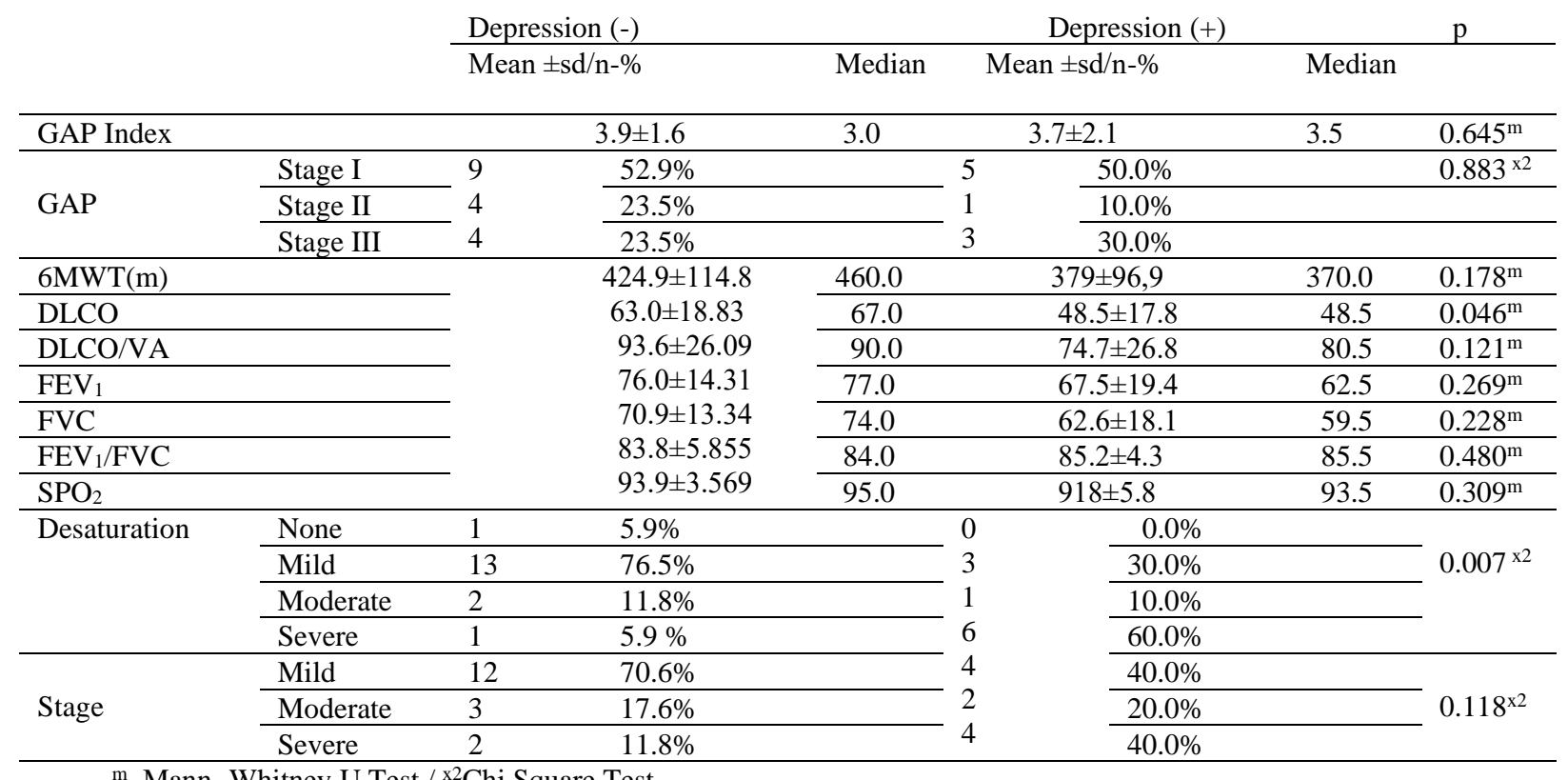

Data are presented as n, mean \pm SD., GAP: Gender-Age-Physiology, 6- (MWT): 6-minute walk test, FEV1: Forced Expiratory Volume in one second, FVC: Forced vital capacity, SPO2: Saturation of Peripheral Oxygen, DLCO:

Diffusing capacity of the lungs for carbon monoxide, 


\section{Discussion}

One of the leading causes of increased impairment and reduced quality of life in older adults is psychological disorders. In particular, in patients with chronic respiratory problems, severe depression, dysthymias (chronic depressive symptoms of moderate severity) and anxiety disorders are widespread (Ng et al., 2007; Maurer et al., 2008; Xu et al., 2008; Schneider et al., 2010).

Anxiety was found in $33.3 \%$ of patients and depression was found in $37 \%$ of the patients with IPF in this research. The patients' average anxiety score was 5.5 and the mean depression score was 5.5 and the mean depression score was 6.2. In patients with anxiety and depression, the desaturation rates were significantly higher and DLCO levels were found to be lower in patients with depression. In our study it was found that hypoxia emerged in IPF significantly contributed to progressing anxiety and depression. In a study (Schneider et al., 2010) involving 35000 patients with chronic obstructive pulmonary disease (COPD), the incidence of depression was almost twice as much in the COPD group, compared to the patients without COPD. And severity of COPD was related developing depression those with COPD (Atlantis et al.,2013).

Findings for IPF are worser than COPD. Some studies have pointed out that depression prevalence varies from $24.3 \%$ to $49.2 \%$ in IPF. (Ryerson et al., 2011; Amin et al., 2014). Severity of disease in IPF is strongly related to depression (Schneider et al., 2010). Dyspnea, pulmonary dysfunction and cough are more related than other variables (Ng et al., 2007; Xu et al., 2008) and are considered to be significant healthrelated quality of life determinants in IPF (Xu et al., 2008).

The findings of present study, which showed that DLCO levels were lower and desaturation rates were higher in depression group, are similar with findings aforementioned. Despite these findings were not correlated some previous studies, this might result from the differences of severity of disease (Lee et al., 2017). The prevalence of anxiety is $13-46 \%$ in COPD outpatients (Willgoss et al., 2013). In addition, patients with comorbid anxiety disorders in COPD are twice as likely as those without anxiety symptoms to have self-reported functional disabilities and a higher incidence of acute exacerbations. Indeed, anxiety disorders are debilating and they may become chronic and raise the risk of hospitalization unless properly treated (Maurer et al., 2008; Atlantis et al., 2013; Holland et al., 2014).

The prevalence of anxiety was found to be $31-$ $60 \%$ in many studies that measured anxiety in patients with IPF (Schneider et al., 2010; Lee et al., 2017). These findings are similar to the results of current study. Possible mechanism of anxiety in patients with chronic pulmonary problems is the relation between respiration and fear. Subjective difficulty on respiration is one of the main somatic symptoms of anxiety disorders, but also this can be a cause in patients with chronic pulmonary problems. Depression is substantially related to a greater risk of exacerbations and hospitalizations in COPD. (Willgoss et al., 2013; Amin et al., 2014; Lee et al., 2017). This is possibly because there is no successful treatment to relieve IPF symptoms unlike with COPD. Therefore, inadequate compliance with recommended medical care because of depression is unlikely to impact treatment results. In researchs examining the quality of life status of these patients, there are several arguments for the increased frequency of depressive symptoms in IPF, (Vries et al., 2001, Xu et al., 2008). There is, however, a substantial lack of major prospective research examining the diagnosis and its impact on the health status of these people.

This study has many limitations. It is a small, observational, retrospective study with no control group. Although HADS is a well-validated depression screening tool, it is not a diagnostic test but based on self-reported questionnaires rather than a complete psychiatric examination. To our knowledge there is no study that determines and compares the level of anxiety and depression in patients with IPF using the HADS scale in our country. Although the number of patients is small, we think that our study will contribute to the literature.

\section{Conclusion}

Anxiety and depression are comorbid diseases related to IPF. The quality of life of patients diagnosed with IPF can be improved by a good psychiatric assessment and adequate supportive care, including antidepressant medication and psychological therapy. 
Ethics Committee Approval: Approval for the study was granted by the medical training board of University of Health Sciences, Ataturk Chest Diseases and Chest Surgery Training and Research Hospital. Decision number :2019/615 Date: 23.01.2019.

Peer-review: Externally peer-reviewed.

Author Contributions: Concept -DY, BAO, MSA; Design- DY, BAO; Supervision- YE; Materials- DY, BAO, MSA; Data Collection and/or Processing- DY; Analysis and/or Interpretation- DY, BAO; Literature Review- DY, MSA; Writing- DYİ MSA; Critical Review- BAO.

Conflict of Interest: No conflict of interest was declared by the authors.

Financial Disclosure: The authors declared that this study hasn't received no financial support.

\section{References}

Akhtar AA., Ali MA., Smith RP. Depression in patients with idiopathic pulmonary fibrosis. Chron Respir Dis. 2013 Aug;10(3):127-33.

Atlantis E., Fahey P., Cochrane B., Smith S. Bidirectional associations between clinically relevant depression or anxiety and COPD: a systematic review and meta-analysis. Chest. 2013 Sep;144(3):766-77.

Amin A., Zedan M., Halima K., Ismail A. Depression In Patients With Idiopathic Pulmonary Fibrosis. AAMJ. 2014 Oct; 12(4).

Aydemir O., Guvenir T., Kuey L., Kultur S. Reliability and Validity of the Turkish version of Hospital Anxiety and Depression Scale. Turkish journal of psychiatry. 1997;8: 280-7.

De Vries J., Kessels BL., Drent M. Quality of life of idiopathic pulmonary fibrosis patients. Eur Respir J 2001 May; 17(5): 954-61.

Holland AE., Fiore JF., Bell EC., Goh N., Westall G., Symons K. et al. Dyspnoea and comorbidity contribute to anxiety and depression in interstitial lung disease. Respirology. 2014 Nov;19(8):121521.

Lee YJ, Choi SM., Lee YJ., Cho YJ., Yoon HI., Lee JH. et al. Clinical impact of depression and anxiety in patients with idiopathic pulmonary fibrosis. PloS one, 2017 Sep 11; 12(9)

Maurer, J., Rebbapragada V., Borson S, Goldstein R, Kunik ME, Yohannes AM. et al. Anxiety and depression in COPD: current understanding, unanswered questions, and research needs. Chest. 2008 Oct., 134(4), 43-56.
Moussavi S., Chatterji S., Verdes E., Tandon A., Patel V., Ustun B. Depression, chronic diseases, and decrements in health: results from the World Health Surveys. Lancet. 2007 Sep 8;370(9590):851-8.

Ng TP., Niti M., Tan WC., Cao Z., Ong KC., Eng P. Depressive symptoms and chronic obstructive pulmonary disease: effect on mortality, hospital readmission, symptom burden, functional status, and quality of life. Arch Intern Med. 2007 Jan 8;167(1):60-7.

Pink K., Boylan J., Hope-Gill B. An Observational Study of Anxiety and Depression in Idiopathic Pulmonary Fibrosis. Advances in Research. 2014 Apr; 2(6): 320-31

Raghu G., Remy-Jardin M., Myers JL., Richeldi L., Ryerson CJ., Lederer DJ. et al. American Thoracic Society, European Respiratory Society, Japanese Respiratory Society, and Latin American Thoracic Society. Diagnosis of Idiopathic Pulmonary Fibrosis. An Official ATS/ERS/JRS/ALAT Clinical Practice Guideline. Am J Respir Crit Care Med. 2018 Sep 1;198(5):e44-e68.

Ryerson CJ., Berkeley J., Carrieri-Kohlman VL., Pantilat SZ., Landefeld CS., Collard HR. Depression and functional status are strongly associated with dyspnea in interstitial lung disease. Chest. 2011 Mar;139(3):609-16.

Ryerson CJ., Arean PA., Berkeley J., CarrieriKohlman VL., Pantilat SZ., Landefeld CS. Et al. Depression is a common and chronic comorbidity in patients with interstitial lung disease. Respirology. 2012 Apr;17(3):525-32.

Schneider C., Jick SS., Bothner U., Meier CR. COPD and the risk of depression. Chest. 2010 Feb;137(2):341-7.

Solano JP., Gomes B., Higginson IJ. A comparison of symptom prevalence in far advanced cancer, AIDS, heart disease, chronic obstructive pulmonary disease and renal disease. J Pain Symptom Manage. 2006 Jan;31(1):58-69.

Willgoss TG., Yohannes AM. Anxiety disorders in patients with COPD: a systematic review. Respir Care.2013 May; 58: 858-66.

Xu W., Collet JP., Shapiro S., Lin Y., Yang T., Platt $\mathrm{RW}$. et al. Independent effect of depression and anxiety on chronic obstructive pulmonary disease exacerbations and hospitalizations. Am J Respir Crit Care Med. 2008 Nov 1;178(9):913-20. 
Yalnız E, Polat G, Demirci F, Deniz S, Karadeniz G, Aydınlı E. et al. Are idiopathic pulmonary fibrosis patients more anxious and depressive than patient's with other interstitial lung disease? Sarcoidosis Vasc Diffuse Lung Dis. 2019;36(4):294-301.

Zheng D., Macera CA., Croft JB., Giles WH., Davis D., Scott WK. Major depression and all-cause mortality among white adults in the United States. Ann Epidemiol. 1997 Apr;7(3):213-8 